\title{
The Contemporary Chinese Writing in the Eyes of Peter Hessler*
}

\author{
Ping Yin \\ College of General Education \\ Heihe University \\ Heihe, China 164300
}

\author{
Guojiang Qi \\ College of Foreign Languages \\ Heihe University \\ Heihe, China 164300
}

\begin{abstract}
Peter Hessler, Chinese name He Wei, has been praised as one of the most thoughtful western writers concerned about modern China by the Wall Street Journal. In the more than ten years of his life in China, he traveled more than half of China. With the elegance of the traveler, he described the Great Wall with image symbol, and the survival predicament of the other in the third space. He has written the family ethics of ordinary people with the attitude of a resident, and the importance of education in China. To some extent, He Wei has certain western ideological bias and utopian imagination upon China, but he has broken through the stereotyped impression of the Chinese image in western literary works, showing a new attitude.
\end{abstract}

\section{Keywords—Hessler; image; Chinese image}

\section{INTRODUCTION}

In 1996, He Wei came to Fuling, China with the identity of "American and Chinese friendly volunteer", and taught students of English major English and American literature at Fuling Normal College (now Changjiang Normal University). In his first summer vacation in Fuling, He Wei traveled to the revolutionary base in the northern part of Shaanxi Province. He was interested in a section of the Great Wall winding through the middle of a desert. This fortress of Ming Dynasty, eighty or ninety kilometers away from the center of Yulin, Shaanxi, extends to two directions in the desert. It stretches west to Jiayuguan, deep in the north mountain of Gansu. To the East, a trail of ruins extends to Shanhaiguan on the coast of the Yellow Sea. The distance between these two passes may be as long as twenty-four thousand kilometers, and Yulin is just a midpoint between them. The Great Wall has already surpassed its original significance. It is not just great, but has become a major prosperous view in rising China. Almost every foreign politician and every tourist will visit the Great Wall in the vicinity of Beijing. It is not so much a city wall as a bridge. It lets the outsider appreciate China's glory with a spectacular view. A few years later, He Wei alone drove along the Great Wall relics in the western. The spectacular of the Great Wall again aroused He Wei sigh: "out of the window, the Great Wall is still and magnificent. The farer I move forward, the greater the building shocks me, not only because of their

*Fund project: This article is one of the results of the annual project of Heilongjiang Philosophy and Social Science Research Program in 2017: Study of Chinese Image in the New-century American Literature - from the perspective of Peter Hessler's works (17WWE365). beauty but also their perseverance". [1] P106

\section{THE PREDICAMENT IN THE THIRD PlaCE}

Fuling is the starting point for He Wei to understand China. The great difference in life between China and the west made him unable to be compatible with everyone. With many confusions and embarrassments, he felt lonely and helpless. From Said's "middle state" theory, Homi K. Bhabha extended the idea of identity: "identity is an intersubjective and acting action that refuses the boundary between the public and the private, psychology and society. It is not a 'self' giving consciousness, but a self 'entering consciousness' through the symbolic fields of the other, including language, social system and unconsciousness". [2] P206 He Wei and another American and Chinese friendly volunteer were arranged in the best building in the school, living with the party secretary and other major cadres at the same floor. For weeks, the school has been giving banquet to treat them almost every other night. One night of the first week, the party had not begun. The teacher in charge of the "foreign office" told them that, "the school decided to install external phone for you, so that you can contact anywhere in China". [3] P10 A few days later, there was another banquet and good news for them. "The school decided to buy another washing machine for them" (The school has bought one before their arrival). [3] P10 A few days later, the school learned from their resume that one of the foreign teachers could play tennis, so "the school decided to buy them tennis". [3] P11 "The two foreign teachers from different degrees and different sides were opposed to the decisions of the school, but the school was determined to fulfill these commitments. These two foreign teachers, in the field of the other, gradually realize that this is an important part of the etiquette in the "other" culture from not adapting to the customs. At the same time, He Wei noticed the Chinese table culture. After drinking with several leaders several times, he found that, in order to express strong emotion and enthusiasm, Chinese people generally drink with their guests beyond their actual drinking capacity. "Most people can't drink a few cups and are red in face. This is one of the reasons why local people are too heavy to drink, and the consequences are not too serious, because most people do not become alcoholics from a genetic perspective. But on a certain occasion, they will drink one or two times, and alcohol will make them extremely uncomfortable, so that they cannot persevere. This is not so much a habit as it is a form of etiquette". [3] p89 The "third 
space" theory was conceived by Homi K. Bhabha on the state of analogue contradiction between China and the West. He believed that "in the process of cultural translation, it would open an "intermittent space" and gap timeliness. It was opposed to the self-consciousness of returning to a primitive 'essentialism', but also opposed to a complete dissociated subject indulging in a 'process"'. [3] P204 In the actual work in Fuling, he changed from inadaption to actively understanding and contacting the other, and found that it was the experience of the process making him feel that he did not disconnect with local culture and life. The school commended on teachers and students participating in Walking in Yan'an in a summer (the greatest thing in memory activity of the Long March). On the school's prize-giving stage were the mayor of Fuling, the party secretary of the school and the principal. He Wei and his companion were also invited to the stage by the Vice Chancellor. All commendation people, including both the leader and the ordinary, in the school dressed neatly. "Team members wore clean white T-shirts, and Adam wore sandals, and I wore an old grey T-shirt, and our naked thighs were very disproportionate to a row of neat trousers". [3] P9 "Everything has a fixed procedure. Every morning, at six o'clock, we heard the wake-up call resounding through the school, and then students do morning exercises. When anther ring rings, students take lessons. The lamplight in the bedroom was extinguished on time at eleven". [3] P16 The regularity made He Wei feel calm and consistent with everyone. "Of course, I have not been in line with them - and in some ways I have never been able to integrate into them. In the first few weeks, I was not out of fit because of the constant procedures centering on me. [3] p15

\section{FAMILY ETHICS}

"Family is the starting point of human civilization and ethical relations. The emergence of family is the first system civilization created by mankind, and its essence is an ethical civilization". [11] P5 The family shapes people's thoughts and actions. Family life makes people understand their identity, what kind of group they are in, and what kind of cultural background they have. Family culture is composed of norms and values related to marriage, family identification and responsibility, socialization of children, residence and family stability. China attaches great importance to family and family ties, which makes He Wei envious. In 2002, in order to better write, He Wei rented an ideal house in San Cha Village, Bohai Town, Huairou County, not far away from Beijing. "From here we can see the Great Wall. From the bottom of the valley, climb up to the hill slope of the Great Wall, and then reach the bricklaying Beacon Tower, which winds along the undulating mountains until it is disappearing on the west horizon. To the West is the Loess Plateau, Ordos Desert and Hexi Corridors. In the past, whenever I saw the Great Wall, I couldn't help coming to visit it". [1] p120 In this wonderful village, He Wei met the villager Wei Ziqi and his family. In contact, He Wei realized that the surname Wei was a huge family in the village, but no few of people of Wei Ziqi's generation stayed in San Cha Village, and his two brothers and two sisters left the village. Almost all villagers at the age of twenty or thirty have left the village. The people who grew up in poor rural areas saw the great changes brought about by reform and opening up to the city when they grew up. Therefore, they choose to leave, and it is a very easy thing. Wei Ziqi also followed his classmates to work in a factory in the suburb of Beijing. $\mathrm{He}$ worked on a rigid assembly line, making him unable to see hope and future. In his mind, the fate of his village did not come to an end. He believed that one day, the village would be a blessing for him to realize his dream. He Wei and Wei Ziqi were the relationship between the tenant and the landlord. The house He Wei rent is Wei Ziqi's nephew's, and now it is all handed to Wei Ziqi. And the housing contract they signed was also written by Wei Ziqi. Wei Ziqi's son Wei Jia got immune thrombocytopenic purpura, He Wei saw the concern of the parents, the grandparents, the uncle, the relatives of the distant houses and the people in the village about the child. Almost all expressed their concern about the child at the different degrees, and they give the family help and support. "That weekend, a lot of relatives and friends came to the hospital to visit the child. The distant relatives took out a pile of hundred bills to the child on the bed, as well as other relatives. At last, it was the child's uncle's turn. He was poorer than others. He also gave a pile of bills, with face values of twenty yuan and ten yuan. [1] p168 Then Wei Ziqi entertained his relatives who came to see his son in the hospital in a nearby restaurant. At the table, Wei Jia's grandfather stood up and drank a very formal toast to He Wei. He said: "we are very grateful to you for your help to Wei Jia". Wei Jia's hospital was contacted with the help of He Wei. During the child's illness, He Wei was silently helping the family of Wei Ziqi. At the dinner table, they also recalled that when Wei Jia was born, one distant relative was still in the army. In order to see the newly born child, he also asked for two days off for the troop. They drank a lot of spirit that day, and they toasted He Wei repeatedly, and finally drank for the health of the children together. After Wei Jia recovered and discharged, Wei Ziqi talked about He Wei driving them to Beijing to find a hospital to everyone he met in the village. "Though I am sure, they have heard the story before. The story was well-known in the village. There is a custom in the village that people will help each other when their neighbours get sick. If someone is hospitalized in the village, other villagers will come to the family's home and send cash. After patient's recovery, the family usually entertains these people with a banquet to express their gratefulness". [1] p171 Because of Wei Jia's disease, He Wei was really involved in the lives of the local villagers for the first time. His practice was recognized by the villagers, and now they greeted He Wei much more than they used to be. In times of difficulty, the care of the relatives and the generosity of the villagers constitute the family-centered ethics.

\section{HARDWORKING STUDENTS IN SEEKING KNOWLEDGE}

The students in Fuling Normal College basically came from the rural areas of Fuling. These students had shining qualities that He Wei has never seen before. He Wei was willing to teach there. "I can hardly imagine a better job. My students are eager to learn, respectful to their teachers and very clever. They smell the flavors of the countryside, night soil and ripe rapeseed, and all the scent from farmland in Sichuan". [3] p26-27 He was shocked by the patriotism and loyalty of the students. "Students are seriously participating in various political study and political gatherings and eager to get the 
opportunity to join the party". [3] p42 He Wei disordered Shakespeare's eighteenth sonnets in the classroom, and let students arrange the correct order of the poem. The students' earnest and uncomplaining hardwork made He Wei feel ashamed at times. "They can put this poem together, and can dismantle it. They can mark the rhythm of poetry. Few American students can do such a thing. There are not many American poems, but it is still difficult for us to distinguish the rhythm. My students in Fuling are not tired and frustrating about the obscure poetry, and they have developed patience". [3] P46 He Wei liked the students he taught very much. "I think they respect teachers' more than American students. My Chinese students like poetry more than most American students". [3] P215. In China, both the poor and the rich attach the importance of education, which arouses the admiration of He Wei. When he traveled in the field, he would always see that children of every family had to study on their own doorsill, and students can always finish all kinds of homework. "This may be one of the most respectful qualities of the local people: they are full of respect for education, and it is really good to teach in such places". [118] p381

\section{CONCLUSION}

In the documentary literature of Hessler about image of China, we clearly perceive that Hessler unavoidably had certain ideological prejudices about the shaping of Chinese image influenced by his own identity and cultural standpoint. Well, Hessler still looked at developing China in a developmental way, and made an objective record of vital China under the reform and opening up policy. At the same time, he also directed his eyes of humanitarianism to the people living on the edge of the society, recorded the psychological changes of ordinary Chinese people during the period of social development, and greatly appreciated the serious attitude and behavior of Chinese people on education. In almost all He Wei's works, we can feel his admiration for the ancient Chinese civilization and interested feelings of the Great Wall in different degrees. The image of Chinese in Hessler's works left a thick ink for the writing of China's image in the new era.

\section{REFERENCES}

[1] (US) Peter Hessler. Country Driving. Translated by Li Xueshun. Shanghai: Shanghai Translation Publishing House, 2012. (美)彼得.海 斯勒.寻路中国 $[\mathrm{M}]$.李雪顺,译.上海:上海译文出版社, 2012.

[2] Homi Bhabha,Unpacking My library...Again, in Iain Chambers and Linda Curti,eds.The Post-colonial Question: Common Skies, Divided Horizons, London: Routledge,1996,p204-206.

[3] (US) Peter Hessler. River Town. Translated by Li Xueshun. Shanghai: Shanghai Translation Publishing House, 2012. (美)彼得.海斯勒.江城 [M].李雪顺,译.上海: 上海译文出版社, 2012.

[4] Liu Haita. From Tradition to Enlightenment: Transformation of Chinese Traditional Family Ethics in Modern Times. Beijing: China Social Sciences Press, 2005. 刘海踏. 从传统到启蒙: 中国传统家庭伦理的 近代擅变[M].北京: 中国社会科学出版社, 2005.3 